\title{
How much processing do nonattended stimuli receive? Apparently very little, but...
}

\author{
CHARLES W. ERIKSEN, JAYSON M. WEBB, and LISA R. FOURNIER \\ University of Illinois, Urbana-Champaign, Champaign, Illinois
}

\begin{abstract}
The early versus late selection issue in attention models was examined by means of a new methodology. Through cues or precues, attention was directed to one location of a multistimulus visual display and, while attention was so engaged, the identity of a stimulus located at a different position in the display was changed. By varying the time after display onset before the stimulus was changed, we controlled the preview time that the original stimulus was represented on the retina. Then, using a marker cue, we directed the subject's attention to the location of the changed stimulus. The subject's response was a timed discrimination between two possible target letters. The data of main interest was the effect of preview time upon the subject's latency in identifying the new target that appeared in the changed location. We found that the preview time of the original stimulus, before RT was affected to the new target, depended upon whether the original stimulus was a neutral (noise) letter or whether it was the alternative target. When the original stimulus was a noise letter, RT's to the new target were just as fast as those obtained in the control condition in which the target was present throughout the preview interval and did not change its identity. Significant effects upon RT were obtained at preview times of $83 \mathrm{msec}$ when the original stimulus was one of the targets that changed to the alternative target. Preview times also varied as a function of precuing. Preview times were correspondingly shortened when the first cue occurred $50 \mathrm{msec}$ before display onset, thus providing an extra $50 \mathrm{msec}$ for attention to be directed to the first display location. The results were interpreted in terms of two separate information-processing systems in the human: an automatic system and an attentional system. Even though a stimulus may have been automatically processed, when the attention system is directed to that stimulus, processing starts at the beginning again.
\end{abstract}

Pashler (1984) has presented a series of experiments that call into serious question a basic assumption of lateselection theories of attention, namely, that stimuli are parallel-processed and identified before attentional processing is engaged. In these experiments, Pashler used a modification of the iconic memory paradigm of Averbach and Coriell (1961). In the paradigm, an overload of visual information is presented for a brief duration and then, at various intervals after the display has been terminated, a bar or cue designates a location in the visual field. The subject is asked to report the stimulus that had occupied that location in the display. The now classic result is that accuracy of report decreases rapidly as the cue is delayed with performance, becoming asymptotic at around $300 \mathrm{msec}$.

In his first experiment, Pashler modified the Averbach and Coriell procedure in several ways. He used displays of eight letters presented in two rows of four characters each. Three probe conditions were used. In the early-probe condition, the probe preceded the display by

This research was supported by Public Health Service Research Career Program Award K6-MH-22014 and by United States Public Health Service Research Grant MH-01206 to the first author. Requests for reprints should be sent to Charles W. Eriksen, Department of Psychology, University of Illinois, Urbana-Champaign, $603 \mathrm{E}$. Daniel, Champaign, IL 61820 .
$200 \mathrm{msec}$ and remained on during the $150 \mathrm{msec}$ of display presentation. With the simultaneous probe, the display and probe came on simultaneously and remained on for $150 \mathrm{msec}$. With the delayed probe, the display was presented first for $300 \mathrm{msec}$, and then the probe occurred. Display and probe then remained on for another $150 \mathrm{msec}$ before they terminated together. Instead of using response accuracy as the dependent variable, Pashler further modified the task to two-choice RT for the letters A and E.

The main experimental manipulation was the discriminability of the display letters. The eight-letter displays consisted of equal numbers of uppercase and lowercase As and Es. Since the lowercase targets are smaller and less discriminable, Pashler reasoned that more time would be required for their identification than for the uppercase forms. Thus, with the early and the simultaneous probe, RT would be longer when the probe designated a lowercase target. However, in the delayed-probe condition, the subject had a 300-msec preview of the display. If preattentive or perceptual processing led to parallel identification of all of the display items, this preview time should have been sufficient for even the less discriminable lowercase letters to have been identified. Consequently, when the probe occurred, the subject had only to respond to an already-identified letter. Thus, a strong version of lateselection theory would clearly predict that the effects of stimulus discriminability would be eliminated in the 
delayed-probe condition. The results failed to support this prediction. As expected, RT was significantly slower for the less discriminable targets in the early- and simultaneous-probe conditions, but it was equally slow in the delayed condition.

In subsequent experiments, Pashler also manipulated letter discriminability by varying contrast, but, in all cases, the slower RT obtained for the less discriminable targets in the early- and simultaneous-probe conditions persisted undiminished when the probe was delayed. The results strongly suggest that the target letter was not encoded or identified until after the probe occurred.

Although Pashler's results are rather surprising to some students of attention, a number of studies have presented strong evidence that, with multielement displays and postcuing, the elements are serially attended and encoded. Sperling (1960) and Averbach and Coriell (1961) interpreted their data in terms of serial encoding. C. W. Eriksen and Colegate (1971) showed that, when two items in a multielement display are postcued, the results are most readily interpreted in terms of successive attending. Furthermore, studies using visual masking in conjunction with the postcuing paradigm have yielded a similar conclusion (C. W. Eriksen \& Rohrbaugh, 1970; Spencer \& Shuntich, 1970). When the cue is in the form of a visual mask, impaired recognition of the probed stimulus has been found to occur at intervals as long as 150 to $200 \mathrm{msec}$ after the display has been terminated. If only single-item displays are presented, the same mask loses its effect at appreciably shorter delay intervals. These results are most readily interpreted as a serial identification of the stimuli in the multielement displays. The extension of the interval for effective masking increases because the cued item must await its turn for identification and, during this wait, the iconic representation decays, making it more susceptible to masking (see C. W. Eriksen \& Schultz, 1978, pp. 13-15, for an analysis of masking in multielement displays).

More recently, van der Heijden, Schreuder, de Loor, and Hagenzieker (1987) and van der Heijden (1984) have analyzed confusion errors in the postcuing task. They found that the frequency of confusion errors first increases and then decreases as the cue delay increases. These results were predicted from an early-selection model of attention.

Pashler's results are impressive and supported by the above-cited research, but there is also strong and diverse evidence that, at least under certain circumstances, multistimuli displays are processed in parallel (e.g., C. W. Eriksen \& Spencer, 1969; Kinchla, 1974; Shiffrin \& Gardner, 1972; Shiffrin \& Schneider, 1977). Thus, early versus late selection continues to be a fundamental issue that divides theories of attention. In the present paper, we employ a novel experimental procedure we have developed that offers promise in providing important evidence on this issue.

The basic idea in this new procedure is to direct attention to one stimulus or area of a multistimuli display and, while focal attention is so engaged, to change the iden- tity of one of the stimuli located in a different area of the display. By varying the time after display onset before the stimulus is changed, we can control the preview time that the original stimulus had been represented on the retina before its identity was changed. Then, using a marker cue, we direct the subject's attention to the location of the changed or substituted stimulus. We are interested in the effect of preview time upon the subject's latency in identifying the new target that has appeared in the changed location.

\section{EXPERIMENT 1}

In Experiment 1, a two-choice RT task was used, with $\mathrm{H}$ and $\mathrm{N}$ as the target letters. A target letter occurred in an eight-letter circular display that was briefly presented. An underline marker was used to cue target location. Instead of a single letter position, two positions were sequentially cued in the display. The first letter position was cued $50 \mathrm{msec}$ before onset of the display; the second position was cued $50 \mathrm{msec}$ after the display onset. Previous research (Hoffman, 1975; Murphy \& C. W. Eriksen, 1987) has shown that a 50-msec interstimulus interval (SOA) between cue and display is sufficient to direct attention to the cued location. Furthermore, we have found clear evidence in previous experiments that this sequential cuing controlled the order in which the stimuli were processed (C. W. Eriksen \& Webb, 1989; Fournier \& C. W. Eriksen, in press).

One of the two target letters was always presented in one of the cued locations. On $50 \%$ of the trials, the target occurred in the first cued position. The main interest, however, was on the $50 \%$ of the trials in which the target occurred in the second cued location: The letters occupying the second cued location were changed $50 \mathrm{msec}$ after display onset.

On approximately one third of these trials $(16 \%$ of the total trials), the letter initially occupying this location was a noise letter, but when the cue occurred, the noise letter was simultaneously changed to one of the target letters (N-T condition). On approximately another one third of the trials, the letter initially occupying the second cued location was one of the targets, but when the cue appeared, the letter changed to the other target letter ( $T_{1}-T_{2}$ condition). On the remaining trials, the original letter was a target that did not change when the cue occurred (control condition). Figure 1 diagrams the temporal sequence of stimulation.

If the sequential cuing controlled the order in which the display positions were searched or attended, then the RT for targets would be longer for targets occurring in the second cued location. The most interesting aspect of Experiment 1 , however, concerns the effects obtained by changing the letters in the second cued location at the time they are cued. According to the late-selection account, all the letters in the display begin being processed in parallel as soon as the display is presented. If this is indeed the case, then changing a noise letter to a target letter 


\section{Total Time}

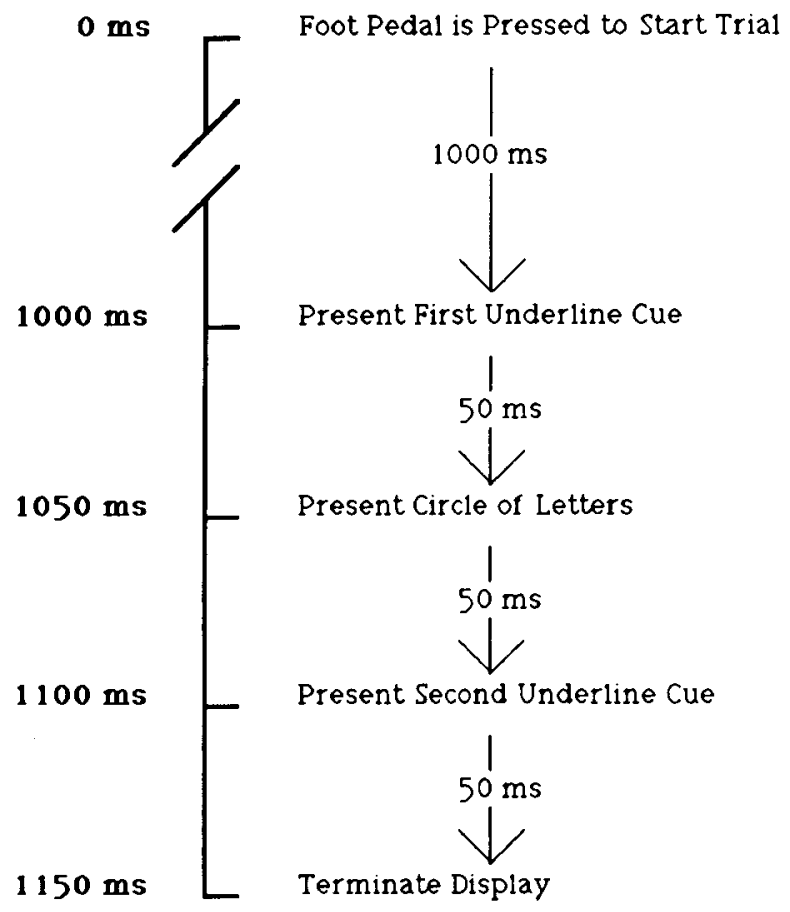

Figure 1. Stimulation sequence in Experiment 1.

or a target letter to the other target letter after a $50-\mathrm{msec}$ preview should have a rather pronounced effect upon both RT and errors. For example, when the target is to occur in the second cued location of the display, the original letter occupying this location is in view for $50 \mathrm{msec}$ before the position is cued. If, during this $50 \mathrm{msec}$, the position was occupied by a nontarget letter, processing would have to start fresh when the nontarget letter was replaced with a target on the advent of the cue. More disruption due to response competition (C. W. Eriksen \& Schultz, 1979) might be expected if the location initially contained one of the target letters and it was replaced by the other target.

If processing or identity encoding of a letter did not begin until that letter was attended, changing the letter would be expected to have little effect upon the advent of the cue. If processing was serial, we anticipated that the sequential cuing of position would control the order in which the display positions were attended. An interval of $100 \mathrm{msec}$ (50 msec SOA plus $50 \mathrm{msec}$ of display duration) was provided for attention to be directed to the first cued location before the second display location was cued. On the basis of a number of precuing experiments (Colegate, Hoffman, \& C. W. Eriksen, 1973; C. W. Eriksen \& Webb, 1989; Murphy \& C. W. Eriksen, 1987; Tsal, 1983), this interval would appear sufficient for attention to be directed to the first location. Other experiments have suggested that approximately 50-70 msec are required for the subject to process a noise letter to the degree of de- termining that it is not a target and then directing attention to another location (C. W. Eriksen \& Yeh, 1985; Treisman \& Gelade, 1980). Therefore, it seems unlikely that attention would have finished processing the first cued location before the second location was cued and the letter in that position replaced. If these assumptions hold, then it is unlikely that attention would be directed to the second cued location before the replacement of a letter in this position occurred.

\section{Method}

Subjects. Five men and 5 women, students at the University of Illinois, served as paid subjects. All were right-handed and had normal or corrected-to-normal vision.

Procedure. Stimuli were presented on a Panasonic Matrox video display and were viewed binocularly at $97 \mathrm{~cm}$. The stimuli were white capital letters on a dark grey background and subtended approximately $0.3^{\circ}$ of vertical visual angle. Luminance was $37 \mathrm{fL}$, as measured by a Spectra Brightness Spotmeter. The control program ran on an RT-11 computer, using stimulus presentation and data collection subroutines from the Pearl-II Subroutine Library, developed at the University of Illinois.

The subjects' task was to discriminate between the target letters $\mathrm{H}$ and $\mathrm{N}$ as quickly and accurately as possible by moving a lever to the left (right) for $\mathrm{H}$ and to the right (left) for $\mathrm{N}$. Direction of lever movement was counterbalanced across subjects. The subjects were instructed that on each trial, only one of the target letters would appear in a circular array with seven nontarget (noise) letters. The diameter of the circular array was approximately $2^{\circ}$ of visual angle; the eight stimulus positions were equally separated along the circumference by approximately $0.78^{\circ}$ of visual angle. The noise stimuli were the letters $M, W$, and $A$. The targets and noise were chosen to be highly mutually confusable at brief presentations. We expected the high confusability among targets and noise to require the subjects to use focal attention.

On each trial, two positions on the circular array were sequentially cued by an underline. One position contained noise and the other contained a target. The two positions cued were either adjacent on the circle or separated by one, two, or three intervening locations. Trials were blocked according to this spacing variable. The subjects started each trial by depressing a foot pedal when their attention was focused on a fixation cross (approximately $0.5^{\circ}$ of horizontal and vertical visual angle) located at the center of the video display. The cross remained on the screen throughout the trial, and the circular array was centered relative to the cross. A delay of $1,000 \mathrm{msec}$ followed the foot-pedal response, then the first underline precue appeared on the screen, marking the location where a stimulus would appear. The precue remained on the screen until the end of the trial. The circular array of letters followed the precue after a 50-msec delay and remained on the screen until the end of the trial. The second cue followed the letter display by $50 \mathrm{msec}$, and the whole display was turned off $50 \mathrm{msec}$ after the second cue appeared. After making a response, the subject received accuracy and RT feedback on the video display. At the end of a block of trials, average RT for correct trials and the number of correct trials for the block were presented on the subject's video display.

The experimental variable of major interest was the letter-change conditions. In the $T_{1}-T_{2}$ change condition, the display, when it first appeared, had a target letter in the position that was subsequently underlined by the second cue. When this second cue appeared, simultaneously with its appearance the target that initially appeared in this position was changed to the other target (e.g., $\mathrm{H}$ changes to $\mathrm{N}$ when the cue appears). In the $\mathrm{N}-\mathrm{T}$ condition, the letter that appeared initially in the second cued position was a noise letter. However, with the onset of the second cue, this noise letter was replaced by one of the target letters (e.g., W changes to N). In the control 
condition, the second cued position initially contained a target letter that did not change when the second cue occurred. Thus, in the two conditions in which the letter changed, the initial letter was present in the display for $50 \mathrm{msec}$ before it was replaced by another letter.

In a block of 32 trials, there were 8 trials for each of the letterchange conditions and 5 trials for the control condition. The remaining 11 trials of the block were trials on which the target occurred in the first cued position. On these trials, a noise letter occupied the second cued position; this letter did not change. The four kinds of trials were randomly intermixed in the trial block.

The subjects served three sessions, each lasting approximately $50 \mathrm{~min}$. The first session was for practice; the data from this session were not analyzed. During each session, all subjects completed 12 blocks of trials.

During a block of 32 trials, each target letter appeared twice in each of the eight display locations. The three noise letters each appeared twice in each location, and one of them appeared three times in each location. The letter that appeared three times in each location was approximately evenly distributed across blocks. The direction of serial cuing, clockwise or counterclockwise, was evenly distributed among the trials and was determined randomly within a block. Thus, the subject could not predict what the direction of cuing would be.

\section{Results}

A three-way ANOVA (target in first vs. second cued location $\times$ spatial separation in the display of cued locations $\times$ subjects) was performed on the response latencies. In this analysis, the data for the second cued location were pooled over the three levels of the stimulus-change variable. There was a significant effect for order of cuing $[F(1,27)=22.92, p<.001]$. When the target occurred in the first cued location, mean response latency was $603 \mathrm{msec}$; when the target occurred in the second cued location, mean response latency was $675 \mathrm{msec}$. The effect for separation did not approach significance $[F(3,27)=$ $.47, p>.20$ ], nor did the interaction of this variable with order of cuing $[F(3,27)=.26, p>.20]$.

The significantly faster latency when targets were in the first cued location is what would be expected if subjects were sequentially processing the cued locations. If the target is found in the first location searched, response latency will be faster than if this location contains a noise letter. In the latter case, some processing time would be required to determine that the location contained a noise letter, and then attention would have to be redirected to the second cued location. The result is consistent with a previous finding using similar displays and sequential cuing (C. W. Eriksen \& Webb, 1989).

The lack of an effect for separation between the cued locations is also consistent with C. W. Eriksen and Webb's findings. In their experiment, there was no reliable or suggestive indication that the search time was affected by the number of noise-occupied display positions intervening between cued locations.

The major concern in the present experiment, however, centers on the changing of the stimulus after the subject has had an opportunity to preview the display. When the target occurred in the second cued location, the subject had had $50 \mathrm{msec}$ to view the display before the second location was cued. Simultaneously with the advent of this second cue, the letter in this cued location changed. In the $T_{1}-T_{2}$ condition, the letter was changed from one of the two targets to the other target. In the N-T condition, the letter changed from a noise letter to one of the target letters. In the control condition, a target letter was replaced by itself. The effects of this stimulus-change variable were analyzed in a within-subjects ANOVA (stimulus change $\times$ separation $\times$ subjects). Again, there was no significant effect for the spatial separation of the cued locations, but, most importantly, there was no significant effect for the type of stimulus change $[F(2,54)=.17, p>.50]$. The interaction was also not significant $[F(6,54)=.84$, $p>.20$ ].

In Table 1, the mean response latencies are shown for the control and the two stimulus-change conditions. As is seen, changing the cued letter has little effect upon the speed with which the subject identifies it. If any processing has occurred for the letter in the $50 \mathrm{msec}$ before the cue appears, the processing is insufficient to contribute to the identification of the letter when the letter remains unchanged in the cued location, nor is it sufficient to impair or delay the processing of a new letter that occurs in this position.

An analysis of errors, in general, supports the results from the response-latency data. The mean percent errors when the target occurred in the first position cued was 13. A $t$ test $[t(9)=5.04]$ for correlated observations showed that this was significantly $(p<.05)$ less than the $16 \%$ errors when the target was in the second cued location. Mean percent errors for the three change conditions are shown in Table 1. A two-way ANOVA (change conditions $\times$ subjects) failed to find a significant effect of the change conditions on identification errors $[F(2,18)=$ $1.51, p>.20]$.

\section{Discussion}

The results of Experiment 1 are consistent with an interpretation that attention is sequentially directed to the individual items in the display. When the first cue appears $50 \mathrm{msec}$ before onset of the display, attention begins to be concentrated upon this spatial location. When the display occurs, processing begins for this letter. If the letter is a target, a rapid response is obtained from the subject. If the space is occupied by a noise letter, the subject spends some processing time determining that the letter is not a target. Attention then is directed to the next location,

Table 1

Mean RTs and Mean Percent Errors Under the Control and the Two Stimulus-Change Conditions

\begin{tabular}{lccc}
\hline & Control & N-T & $T_{1}-T_{2}$ \\
\hline Mean RT & 675 & 673 & 676 \\
Mean \% Errors & 14 & 17 & 18 \\
\hline
\end{tabular}

Note-Mean RTs are expressed in milliseconds. 
which by this time has been cued. As a consequence of this serial processing, targets, when they occur in the first cued locations, are responded to, on the average, $72 \mathrm{msec}$ faster than when they occur in the second cued location.

The most important conclusion suggested by these results, however, is that letters in the display receive, at the most, only very minimal processing until they are attended. The subjects had had a 50-msec preview of the eight-letter display before the second location was cued. Simultaneously with the occurrence of this cue, the letter in this location continued unchanged, changed from a noise letter to one of the targets, or changed from a target to the other target. Yet, response latency under these three conditions did not differ reliably or appreciably. On the basis of other experiments studying the RT-SOA function obtained by precuing locations in comparable displays (C. W. Eriksen \& Webb, 1989; Murphy \& C. W. Eriksen, 1987), attention was directed or being directed to the first cued letter when the second position was cued and the letter changed. Since changing the letter had no effect upon RT, even when response competition would be involved, no progress appears to have been made in identification of the letter in the second cued location while attention was engaged elsewhere. This result is a serious problem for strong versions of late-selection theory and provides clear support for Pashler's (1984) findings. At the most, only low-level processing, such as figure-ground differentiation, would appear to have taken place for the nonattended letters in the display.

Although the failure to find a letter-change effect would seem to reinforce the conclusion of serial attention to the display letters, it is possible to model the results consistent with limited divided attention and parallel processing. Shaw (1978) proposed a resource model of attention in which resources could be simultaneously allocated to different locations in the visual field or to different tasks. Applied to the present experiment, this model would account for the results by proposing that, with the advent of the first cue, some resources were directed to that location. When the second cue occurred, some of the remaining resources were allocated to the second location. Thus, both cued letters could be undergoing processing simultaneously; but, since processing began earlier on the first cued location, targets located there would, on the average, be identified sooner.

This model allows for parallel processing of stimuli, but it does not provide an account of the data consistent with late-selection explanations. Processing of the two locations may overlap in time, but attentional resources are still required for stimulus identification. If significant processing occurred for the second location before attentional resources were directed there, we would still expect to find interference effects when the target changed, relative to when it remained the same.

It is possible that the $50-\mathrm{msec}$ preview of the display was too brief for more than elementary processing to get under way before the stimulus changes occurred. B. A. Eriksen and C. W. Eriksen (1974), Hoffman (1975), and Rohrbaugh and C. W. Eriksen (1975) have reported a phenomenon comparable to "perceptual inertia." In the Rohrbaugh and C. W. Eriksen experiments, two checkerboard patterns of lighted squares were presented sequentially in a tachistoscope. If presented simultaneously, the patterns of squares aligned so as to produce either vertical or horizontal stripes. The subject's task was to respond as rapidly as possible with a vertical or horizontal discrimination. The major purpose of the experiments was to study visual temporal integration over time, but an ancillary finding was that RT remained constant as the interstimulus interval between the onset of the first pattern and onset of the second increased to $50 \mathrm{msec}$. In other words, if RT was measured from the onset of the first checkerboard, the second checkerboard that completed the vertical or horizontal stripes could be delayed up to at least 50 msec without increasing RT.

Clearly, the first $50 \mathrm{msec}$ of stimulation did not result in any processing that was beneficial to the verticalhorizontal discrimination. The experiments of B. A. Eriksen and C. W. Eriksen (1974) and Hoffman (1975) used different tasks but revealed the same phenomenon: The first 40 to 50 msec of processing following stimulus onset may not be able to make use of information in the stimulus that is critical for discrimination. There is a phenomenon similar to perceptual inertia during which the processing system is being turned on, so to speak, and until the system is revved up, the presence of discriminatory detail cannot be used. In Experiment 2, we addressed this issue.

\section{EXPERIMENT 2}

Experiment 2 was essentially a replication of Experiment 1 , but with some modifications. In Experiment 1, the second cue appeared $50 \mathrm{msec}$ after the display had been presented and, when a letter was changed, the change was made simultaneously with the onset of the cue. Experiment 2 differed by introducing a stimulus onset asynchrony (SOA) of 34,50 , or 83 msec between the onset of the second cue and the change of the letter in that position from a noise letter to a target or from one target to the other. Thus, the original letter in the second cued position had a preview of 84,100 , or $133 \mathrm{msec}$ before it changed to another letter.

The results of the experiments of B. A. Eriksen and C. W. Eriksen (1974) and Rohrbaugh and C. W. Eriksen (1975) indicated that about $50 \mathrm{msec}$ was the upper limit for delay in the critical discriminatory information before RT began to increase. If the lack of stimulus-change effects in Experiment 1 was due to too brief a preview of the display before the letter changed, the use of SOAs up to $83 \mathrm{msec}$ should remedy this problem and also provide an estimate of how long it takes for attention to shift from processing the first cued area. 


\section{Method}

Subjects. Four men and 4 women, students at the University of Illinois, served as paid subjects. All had normal or corrected-tonormal vision, and none had served in Experiment 1. Each subject served in three sessions, each of which lasted approximately $50 \mathrm{~min}$.

Procedure. The equipment and procedure were the same as for Experiment 1, with the following exceptions. Instead of the letter changes occurring simultaneously with the advent of the second cue, the letter initially appearing in this display position remained for 34,50 , or $83 \mathrm{msec}$ after the occurrence of the cue. Then, in the $T_{1}-T_{2}$ condition, it changed from one target letter to the other target letter or, in the N-T condition, from a noise letter to one of the targets. Thus, the original letter in the second cued position had a preview time of 84,100 , or 133 msec before it was replaced by the target for that trial. This temporal sequence of stimulation is diagramed in Figure 2.

To accommodate the SOAs between the onset of the second cue and the changing of the cued letter, the duration of the display was increased to $183 \mathrm{msec}$. Thus, the stimulation sequence in Experiment 2 was as follows: Cue 1 appeared, followed $50 \mathrm{msec}$ later by the eight-letter display. After another $50 \mathrm{msec}$, Cue 2 appeared, and then, if a letter-change trial was to be presented, the second cued letter was replaced after an SOA of 34,50 , or $83 \mathrm{msec}$ from the onset of the second cue.

With this procedure, in the letter-change conditions, the initial letter had a preview of 84,100 , or $133 \mathrm{msec}$, depending upon SOA,

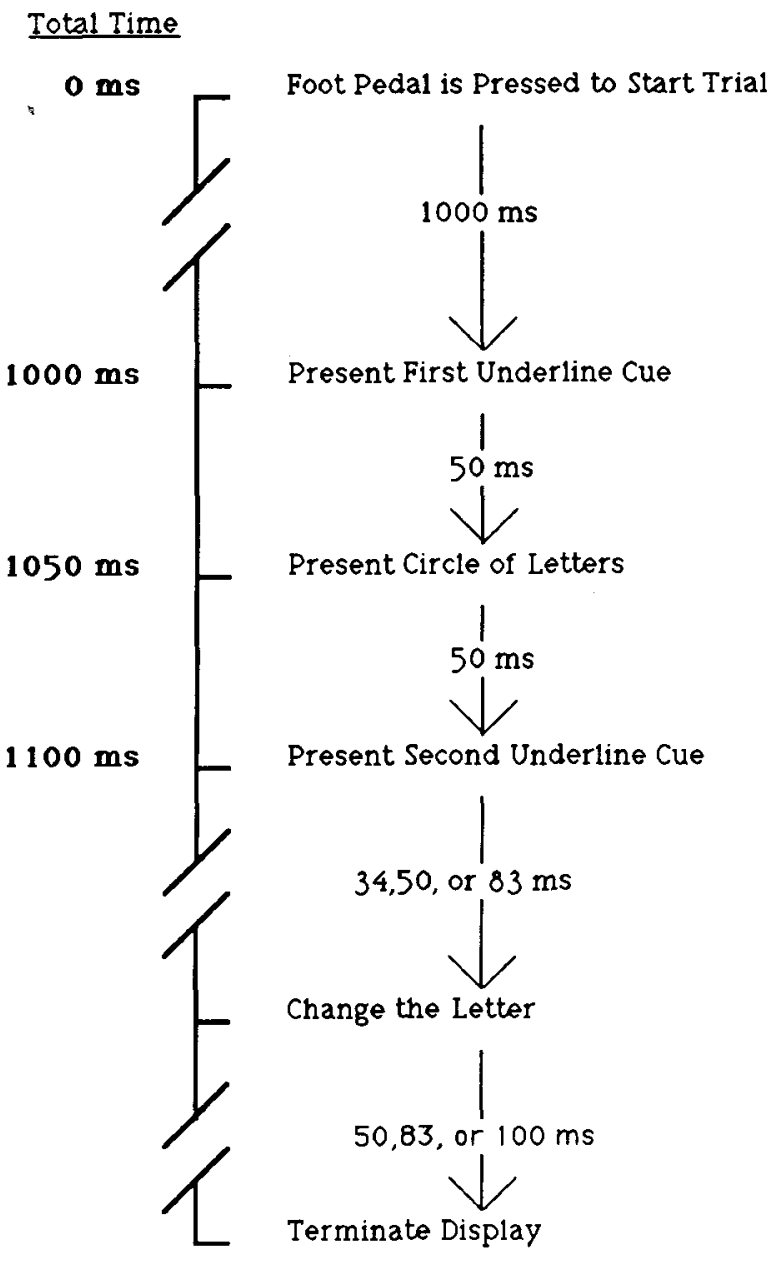

Figure 2. Stimulation sequence in Experiment 2.
Table 2

Mean RTs and Mean Percent Errors for the Control and the Two Stimulus-Change Conditions at Each of the Three Change Delays

\begin{tabular}{|c|c|c|c|c|c|c|}
\hline \multirow[b]{2}{*}{$\begin{array}{l}\text { Change } \\
\text { Delay }\end{array}$} & \multicolumn{2}{|c|}{ Control } & \multicolumn{2}{|c|}{$\mathrm{N}-\mathrm{T}$} & \multicolumn{2}{|c|}{$T_{1}-T_{2}$} \\
\hline & $\begin{array}{c}\text { Mean } \\
\text { RT }\end{array}$ & $\begin{array}{c}\text { Mean \% } \\
\text { Errors }\end{array}$ & $\begin{array}{c}\text { Mean } \\
\text { RT }\end{array}$ & $\begin{array}{c}\text { Mean \% } \\
\text { Errors } \\
\end{array}$ & $\begin{array}{c}\text { Mean } \\
\text { RT }\end{array}$ & $\begin{array}{c}\text { Mean \% } \\
\text { Errors }\end{array}$ \\
\hline 34 & 605 & 9 & 587 & 14 & 592 & 15 \\
\hline 50 & 611 & 14 & 590 & 13 & 623 & 18 \\
\hline 83 & 602 & 13 & 639 & 10 & 654 & 28 \\
\hline
\end{tabular}

Note-Change delays and mean RTs are expressed in milliseconds.

before it was replaced with the target letter for that trial. Note that, since the total display duration was $183 \mathrm{msec}$, when a new letter appeared in the second cued location, it was present in the display for variable durations. When the change SOA was $83 \mathrm{msec}$, the new letter was present for viewing for only $47 \mathrm{msec}$ before the entire display terminated. When the SOA was $34 \mathrm{msec}$, the new letter was present for $96 \mathrm{msec}$. In the control condition, in which the letter did not change but was replaced by itself, the second cued letter was present for the full $183 \mathrm{msec}$. We did not anticipate that these differences in viewing time for the changed letter would be a problem. In Experiment 1, the viewing time for the changed letters was $50 \mathrm{msec}$, and pilot experimentation had shown that viewing time for single target letters that varied from 50 to $200 \mathrm{msec}$ gave essentially the same RTs.

\section{Results}

The mean RT for targets when they occurred in the second cued location pooled over change conditions and separations was $613 \mathrm{msec}$; the mean RT for targets when they occurred in the first cued location was $554 \mathrm{msec}$. A $t$ test $[t(7)=4.77]$ for correlated observations showed the difference to be significant beyond the .01 level. This finding is comparable to the results from Experiment 1 and is consistent with what would be expected if the subjects were processing the first cued location first on the majority of trials.

The RTs for correct responses when the targets occurred in the second position cued were analyzed in a four-way ANOVA (change conditions $\times$ change SOAs $\times$ display separations $\times$ subjects). As in Experiment 1 and in a prior experiment (C. W. Eriksen \& Webb, 1989), there was no significant effect for separation or distance between the cued locations, nor did this variable interact with the other variables. Our main interest, however, was with the interaction between change conditions and change delays, and this interaction was significant $[F(4,84)=6.77, p<$ $.001]$. The form of this interaction is shown in Table 2 .

The table shows that the RTs are essentially the same for the two change conditions, $T_{1}-T_{2}$ and $N-T$, and for the no-change control when the letter changes are delayed for $34 \mathrm{msec}$ following the cuing of the second location. At the 34-msec SOA, the subject has had an 84-msec preview of the display before the noise letter is replaced by a target $(\mathrm{N}-\mathrm{T})$ or one of the target letters is replaced by the other target letter $\left(T_{1}-T_{2}\right)$. At the 50 -msec change delay (a preview of $100 \mathrm{msec}$ ), replacing a noise letter with one of the targets still does not raise RT to this second letter over the RT obtained when the letter does not change its identity. There is a strong suggestion, though, 
that at this SOA, changing the original letter from one of the targets to the other target does increase RT. At this SOA, RT for the $T_{1}-T_{2}$ condition is significantly longer than for the $\mathrm{N}-\mathrm{T}$ condition at the .05 level by planned comparison.

When the preview time is $133 \mathrm{msec}$ ( $83-\mathrm{msec}$ SOA), there is clear evidence that changing the stimulus letter in the cued location has interfered with processing. The interference is greater if the change is from one target to the other target than if the change is from a noise letter to a target, but the difference is not significant $(p>.05)$. Both of these conditions, however, produce RTs that are significantly longer ( $p<.01$, by planned comparison) than are those obtained if the second cued letter remains unchanged. In the latter control condition, RT remains essentially constant across the three SOAs.

Analysis of error scores, for the most part, correspond with the RT data. A three-way ANOVA of these data (change conditions $\times$ change delay $\times$ subjects) showed a significant effect for change conditions $[F(2,28)=$ $23.45, p<.001]$ and a significant interaction between change conditions and change delay $[F(4,28)=7.35$, $p<.001]$. Inspection of the error data in Table 2 shows the basis of these significant effects.

As with the RT data, performance under the control and the $\mathrm{N}-\mathrm{T}$ conditions was about the same at the 34- and 50 -msec SOAs. The only discrepancy with the RT data is at the 83-msec SOA. The N-T condition showed a significant increase in RT at this SOA; however, percent errors for $\mathrm{N}-\mathrm{T}$ did not increase but remained at the level of errors for the no-change control condition. Percent errors for the $T_{1}-T_{2}$ condition, on the other hand, were slightly larger at the 34- and 50-msec SOAs and increased quite markedly at the longest SOA.

\section{Discussion}

Experiment 2 was addressed to our concern that the failure to obtain any effects due to letter changes in Experiment 1 may have been due to a preview time that was too short for significant stimulus processing to have occurred. The results of Experiment 2 extend the null effects of stimulus change to a preview time of at least $84 \mathrm{msec}$ and, in the case of the N-T condition, to $100 \mathrm{msec}$. This clearly exceeds the $40-50 \mathrm{msec}$ of possible processing dead time that had been suggested in several experiments (B. A. Eriksen \& C. W. Eriksen, 1974; Hoffman, 1975; Rohrbaugh \& C. W. Eriksen, 1975). In these experiments, failure to provide the critical detail necessary for discrimination after a $50-\mathrm{msec}$ interval resulted in increases in RT. Times of 84 to $100 \mathrm{msec}$ are too long for a presumption that no appreciable stimulus processing occurs during this interval, particularly given the relatively high energy levels of the stimuli. Instead, the results support a conclusion that very little stimulus processing occurs before focal attention is directed to the stimulus.

The question can be raised as to whether the increase in RT and errors in the $\mathrm{N}-\mathrm{T}$ and $\mathrm{T}_{1}-\mathrm{T}_{2}$ conditions at the 83-msec change delay might not have resulted from too short a duration for the new target that appeared. The total duration of the letter display was $183 \mathrm{msec}$. The second position was cued $50 \mathrm{msec}$ after the display onset; with the 83-msec SOA for stimulus change, the correct target letter had a viewing time of only $50 \mathrm{msec}$, whereas, with the 34- and 50-msec SOAs, the correct target letters had viewing times of 99 and $83 \mathrm{msec}$, respectively. It is very unlikely that the variable durations of the changed target affected performance. In Experiment 1, the viewing time for the changed targets was also $50 \mathrm{msec}$, and there was no significant effect in terms of either errors or RT for the changed targets; in the control condition, the target had a viewing time of 100 msec. Thus, we conclude that, in Experiment 2, the increase in RT when the letter was changed $83 \mathrm{msec}$ after its position was cued was the result of fast switches of attention on a small percentage of the trials to the second cued position. On these short latency attention switches, processing of the letter would have begun before the letter change occurred with a consequent disruption in processing of the subsequent appearing letter.

This interpretation is also supported by the finding that the errors increased significantly more in the $T_{1}-T_{2}$ condition than they did in the $\mathrm{N}-\mathrm{T}$ condition. If attention had begun to process a letter and then the letter was changed from a noise letter to a target letter, RT would be expected to increase, but not necessarily errors. Even if the noise letter had been processed to recognition, it would not lead to a response. On the other hand, if one of the target letters had been processed to recognition before it was replaced by the other target letter, it seems likely that a response to the first target letter would occasionally occur, which, of course, would be scored as an error.

If we assume that processing of a display letter does not begin until attention is directed to it, the methodology that we have employed in these experiments also permits an estimate of the minimal time required to direct attention to a position in the visual field. In Experiments 1 and 2, two relocations of attention were required. If we assume that attention was successively directed to the cued locations, we can logically infer what processes must have occurred.

First, the cue must be detected and location information must be processed. Detection can be presumed to have a latency, and the processing of the location information probably has a variable time. Second, it is likely that there is a variable latency in activating attention, as well as in orienting attention to the cued location.

In Experiment 2, we found little evidence of processing a target in the second cued location when the interval between the first cue and stimulus change in the second cued location was as long as $150 \mathrm{msec}$ (temporal sequence: first cue, 50-msec SOA, display, 50-msec SOA, second cue, 50-msec SOA, second cued stimulus changes). When the interval between the first cue and stimulus change equaled $183 \mathrm{msec}$, we obtained evidence that changing the identity of the second cued stimulus affects processing. During this $183 \mathrm{msec}$, a subject not only 
would have had to detect the first cue and direct attention to the cued location, but also to process the noise letter in the first cued location far enough to be able to discard it as a noise letter and to detect and process the second cue and reorient attention to this cued location. (Note that this $183-\mathrm{msec}$ time value would represent the shortest latencies for the fastest subject[s] rather than the mean time required to begin processing the second cued letter.)

The literature contains several estimates of the times required to detect a location cue and direct attention to a position in visual space, as well as to process a noise letter enough to decide that it is a noise letter and then to reorient attention to another display letter. Data from Hoffman's (1975) experiment suggest that the time required to detect a location cue and direct attention to the cued location has a minimal value of between 50 and $100 \mathrm{msec}$. Hoffman used circular displays made of eight numerals. The numerals were constructed of seven straight line segments. Choice RT was employed, with 3 and 5 as the targets. In one condition of the experiment, the display presented contained seven noise numbers and the eighth position contained only three horizontal lines. A black bar, presented simultaneously with the display, cued this location. At various SOAs after display onset, two vertical lines were added to the three horizontal lines at the cued location, thus forming either a 3 or a 5 . If the subject's RT was timed from the onset of the display, the value of this RT remained constant for SOAs at least as long as $50 \mathrm{msec}$. In other words, no significant processing of the cued location appeared to have taken place during the first $50 \mathrm{msec}$ of display exposure. At $100-\mathrm{msec}$ SOA, a small increase in RT occurred; at longer SOAs, RT increased in direct proportion to increases in SOA.

Estimates of the time required to process a noise letter and then reorient attention to another letter are available from the experiments of C. W. Eriksen, Goettl, St. James, and Fournier (1989), C. W. Eriksen and Yeh (1985), and Treisman and Gelade (1980). These experiments used different methodologies, but the time values converge on a range of 50 to $70 \mathrm{msec}$. We might expect the time to vary somewhat with the difficulty of the discrimination between noise letters and targets. It is possible that noise letters that are quite dissimilar from the targets require less processing to determine that they were nontargets than do letters that were quite similar.

In Experiment 2, we obtained a minimal time in excess of $150 \mathrm{msec}$ for subjects to direct focal attention to the first cued location, process the noise letter in that location sufficiently to determine that it is a nontarget, and then redirect attention to the second cued location. If we assume that the cues are detected and processed preattentively (a reasonable assumption, for how else would focal attention be directed to a location or object?), then the 150-msec minimal time that we obtained in Experiment 2 is quite comparable to what would be predicted from the data of Hoffman (1975) and the other investigators (C. W. Eriksen et al., 1989; C. W. Eriksen \& Yeh, 1985; Treisman \& Gelade, 1980). The present data do not, how- ever, permit us to separate the time for detecting the first cue and orienting focal attention to this cued location from the overall time to process both cued locations. In Experiment 3 , we obtained an estimate of the minimal time required to detect and process a location cue and to begin processing the stimulus in this cued location.

\section{EXPERIMENT 3}

One condition of Experiment 3 was quite similar to Hoffman's (1975) procedure. In our simultaneous condition, an eight-letter circular display was presented with one of the letters underlined (cued). The subject was instructed that the target letter would be in this cued location. At 34,50 , or $83 \mathrm{msec}$ after the display was presented, the letter in the cued location was changed either from a neutral noise letter to one of the targets $(\mathrm{N}-\mathrm{T})$ or from one target letter to the other target letter $\left(T_{1}-T_{2}\right)$. In a control condition, a target letter, which did not change, initially appeared in the cued location.

In a second condition (precue condition), the location of the target was precued (underlined) $50 \mathrm{msec}$ before display onset. Again, the letter initially occupying this position either remained unchanged or was changed 34,50 , or $83 \mathrm{msec}$ after display onset from a noise letter to one of the target letters or from one target letter to the other. The precue condition was used in case the minimal latency to detect and process the cue and direct attention to the location exceeded $83 \mathrm{msec}$. By precuing location before display onset, we provided another $50 \mathrm{msec}$ of time for attention to be directed to the cued location. Thus, Experiment 3 was sensitive to time intervals for assessing attentional deployment from 34 to $133 \mathrm{msec}$.

\section{Method}

Subjects. Four women and 3 men, students at the University of nlinois, served as paid subjects. All had normal or corrected-tonormal vision.

Procedure. Apparatus, stimuli, and displays were the same as those used in Experiments 1 and 2. In Experiment 3, only a single display position was cued; the subject was informed that the target letter would occupy this cued location. In the precue condition, an underline cue appeared $50 \mathrm{msec}$ before the onset of the eight-letter circular display. At SOAs of 34,50 , or $83 \mathrm{msec}$ after onset of the letter display, the letter in the cued location was either changed from a noise letter to one of the two targets, changed from one of the targets to the other target, or was initially a target and was not changed. In the simultaneous-cue condition, the underline cue appeared simultaneously with the onset of the letter display. Other than this difference in the temporal occurrence of the cue, the simultaneous and precue conditions were the same.

The subjects served in three sessions, the first of which was practice. In each of the two experimental sessions each subject received 8 blocks of 36 trials. Trials were blocked by cuing condition. Within blocks, each of the three stimulus-change conditions and each of the three SOAs occurred equally often in a pseudorandom manner.

\section{Results and Discussion}

A four-way ANOVA (cuing condition $\times$ target-change condition $\times$ change delay $\times$ subjects) was performed on both the RT and the error data. For RTs, the main effect 
for cuing condition was significant $[F(1,24)=147$, $p<.001]$, as was the interaction between cuing condition, change condition, and change delay $[F(2,24)=8.73$, $p<.001]$. The ANOVA for the error data yielded no significant effects. Table 3 shows the mean RTs across subjects for the three change delays under each of the target-change conditions for simultaneous and for $50-\mathrm{msec}$ precuing. Corresponding mean percent errors are also shown in Table 3.

The RTs under the precuing condition were uniformly faster for all target- and delay-change conditions. This result is consistent with a substantial body of research that has shown the facilitating effects of location precues upon visual discriminations (e.g., Colegate et al., 1973; C. W. Eriksen \& Hoffman, 1973; Tsal, 1983).

Our major interest, however, is the three-way interaction between cuing, target change, and change delays. As is seen in Table 3, with the simultaneous location cue, RTs to target letters do not differ appreciably between the control and the $\mathrm{N}-\mathrm{T}$ conditions. Changing a noise letter in the cued location to one of the targets even $83 \mathrm{msec}$ after the display has been presented increases RT only 2 msec over the control condition in which a target is initially presented in the cued location and does not change. Mean RTs are somewhat longer when the change is from one target to the other target, but these mean RTs do not differ significantly from the means in the control and N-T conditions (by planned comparisons, $p>.05$ ). Further evidence that the differences may be due to chance variation is found in the observation that RTs for the $T_{1}-T_{2}$ condition do not increase with increasing values of change delay. Changing a target to the other target after a 34- $\mathrm{msec}$ delay yields the same RT as when the change is delayed $83 \mathrm{msec}$.

The significant three-way interaction is due to differences in the target-change conditions when the display is preceded by a location precue. Delaying the change 34 or 50 msec does not materially affect $\mathrm{RT}$ in either the $\mathrm{N}-\mathrm{T}$ or the $T_{1}-T_{2}$ condition over the control condition, but, when the change is delayed $83 \mathrm{msec}$, there is a substantial increase in RT. Planned comparisons show that the

Table 3

Mean RTs and Mean Percent Errors for the Control and the Two Stimulus-Change Conditions Obtained for Each of the Three Delay Periods Between Display Onset and Letter Change

\begin{tabular}{|c|c|c|c|c|c|c|}
\hline \multirow[b]{2}{*}{$\begin{array}{l}\text { Change } \\
\text { Delay }\end{array}$} & \multicolumn{2}{|c|}{ Control } & \multicolumn{2}{|c|}{$\mathrm{N}-\mathrm{T}$} & \multicolumn{2}{|c|}{$T_{1}-T_{2}$} \\
\hline & $\begin{array}{l}\text { Mean } \\
\text { RT }\end{array}$ & $\begin{array}{c}\text { Mean \% } \\
\text { Errors }\end{array}$ & $\begin{array}{l}\text { Mean } \\
\text { RT }\end{array}$ & $\begin{array}{c}\text { Mean \% } \\
\text { Errors }\end{array}$ & $\begin{array}{l}\text { Mean } \\
\text { RT }\end{array}$ & $\begin{array}{c}\text { Mean \% } \\
\text { Errors }\end{array}$ \\
\hline \multicolumn{7}{|c|}{ Simultaneous-Cue Condition } \\
\hline $\begin{array}{l}34 \\
50 \\
83\end{array}$ & $\begin{array}{l}560 \\
556 \\
552\end{array}$ & $\begin{array}{r}11 \\
7 \\
8\end{array}$ & $\begin{array}{l}547 \\
551 \\
554\end{array}$ & $\begin{array}{l}5 \\
6 \\
7\end{array}$ & $\begin{array}{l}578 \\
572 \\
578\end{array}$ & $\begin{array}{r}7 \\
6 \\
12\end{array}$ \\
\hline \multicolumn{7}{|c|}{ 50-msec Precue Condition } \\
\hline $\begin{array}{l}34 \\
50 \\
83\end{array}$ & $\begin{array}{l}507 \\
496 \\
493\end{array}$ & $\begin{array}{l}4 \\
5 \\
1\end{array}$ & $\begin{array}{l}494 \\
503 \\
541\end{array}$ & $\begin{array}{l}2 \\
5 \\
7\end{array}$ & $\begin{array}{l}504 \\
516 \\
564\end{array}$ & $\begin{array}{r}2 \\
6 \\
19\end{array}$ \\
\hline
\end{tabular}

Note-Change delays and mean RTs are expressed in milliseconds. increases are significant $(p<.01)$ and that the increase for the $T_{1}-T_{2}$ condition is significantly greater than is the increase for $\mathrm{N}-\mathrm{T}(p<.05)$.

Although the ANOVA of the percent errors did not show any significant effects, we note that $12 \%$ errors occur for the $T_{1}-T_{2}$ condition at the 83-msec change delay with the simultaneous cue and $19 \%$ with the precue. Although the $12 \%$ errors are probably not meaningful under the simultaneous cue ( $11 \%$ errors occurred in the control condition), there is reason to believe that the $19 \%$ errors at the 83-msec change delay with the precue reflects that at least some of the subjects on a small proportion of the trials perceive the first target presented in this location and respond to it (which is, of course, counted as an error). This belief is strengthened by the significant increase in RT for the $T_{1}-T_{2}$ condition at this change delay and by the observation that, other than the $19 \%$ errors, the largest error percentage observed with precuing was only $7 \%$. An increase in errors would not necessarily be expected under the N-T condition if some subjects were occasionally recognizing the first presented letter at the 83-msec change delay, since the first letter was not a target and would not have led to a response.

We are assuming that performance on the task in Experiment 3 requires that the subject first detect the location cue and process it. Some measurable time then is required to direct attention to this location. On the basis of the results of this and the previous two experiments, it would appear that little or no processing of the letters in a display occurs until they are individually attended. If this is the case, the data of Experiment 3 strongly suggest that the minimum time required for the fastest of our 7 subjects to process the cue and direct attention to the cued location was somewhere between 100 and $133 \mathrm{msec}$. We base this estimate upon the following reasoning. In the simultaneous-cue condition, there was no detectable effect upon RT when the letter initially presented in the cued location had as much as an 83-msec preview before it was changed to the correct target for that trial. When the location was precued by $50 \mathrm{msec}$, this had the effect of providing an additional $50 \mathrm{msec}$ for processing location information. But here again, no effect of stimulus change was observed when the total time for location processing and stimulus preview totaled $100 \mathrm{msec}$. Only when the change delay was extended to $83 \mathrm{msec}$ (133 $\mathrm{msec}$ total for cue processing and orienting attention) was there a significant and appreciable effect for changing a noise letter to a target or replacing one target with the other.

This estimate of the minimum time required to orient attention to the cued location can be compared with the estimate derived from Hoffman's (1975) data with quite comparable eight-letter displays. His data suggest a time value of between 50 and $100 \mathrm{msec}$, somewhat shorter than we obtained. This discrepancy could be due to individual differences, but it also may reflect a difference in discriminability of the location cue used in the two experiments. Hoffman used a bar marker that was placed external to the circular display, which would seem to be a 
more salient cue than the underlining of a letter position that we used. Thus, the slightly shorter time estimates obtained from Hoffman's data may be due to less time required to detect and process location information.

Experiment 3 provides clear evidence of the role of focal attention in stimulus identification. Here, holding constant the viewing time of a stimulus, we were able to vary the amount of processing this stimulus received by manipulating a focal attention variable. In the simultaneous-cue condition of Experiment 3, there was no effect upon RT or errors when the initial stimulus was changed from a noise letter to a target or from one target to the alternative target after a preview time of $83 \mathrm{msec}$ of the original stimulus. However, if an additional $50 \mathrm{msec}$ was provided for attention to be directed to the stimulus location, as in the precue condition, stimulus change after $83 \mathrm{msec}$ resulted in an appreciable increase in RT in both the $\mathrm{N}-\mathrm{T}$ and the $T_{1}-T_{2}$ conditions and an increase in errors in the $T_{1}-T_{2}$ condition. In both the simultaneous-cue and the precue conditions, the stimulus was available to the visual system for the same duration, but, in the latter condition, an additional $50 \mathrm{msec}$ was available for attention to focus on the relevant stimulus.

\section{GENERAL DISCUSSION}

Pashler (1984) concluded that the results of his experiments were incompatible with strong versions of lateselection theories. The results of our three experiments are not only highly consistent with those of Pashler, but they would appear to require the conclusion that no detectable processing of visual stimuli occurs until focal attention arrives at the location of the stimulus. We have found that a stimulus can be present at a nonattended location in the visual field for well over $100 \mathrm{msec}$ and yet the discriminative RT to that stimulus is no faster than the RT to a new stimulus whose onset coincides with the attending of that spatial location. The conclusion is quite clear that, when a stimulus has focal attention directed to it, processing of the stimulus by the attentional system begins from scratch.

While the present results and those of Pashler (1984) would seem to pose considerable difficulty for lateselection models of attention, there is, nonetheless, a considerable body of experimentation (see Duncan, 1980) that supports the belief that stimulus identification can occur without focal attention. Not only is this experimentation relevant, but common sense tells us that the level of perceptual motor skills that humans can develop cannot be supported and directed by a relatively slow attentional system that serially or sequentially processes each and every stimulus that is required to guide these complex acts. One solution is to posit a separate information-processing system. LaBerge (1973) and Shiffrin and Schneider (1977) have set forth the criteria for such a system in terms of automatic processing (see Shiffrin, 1988, for a summary of the research literature on automatic processing). Essentially, the automatic system contains innate behaviors, as well as stimulus response connections that are well learned and practiced.

The relation of the concepts of automatic and preattentive processing have not been clearly explicated. The term preattentive implies that this is a precursor to focal attention, whereas automatic processing does not require that the stimuli processed in this system enter into focal attention or awareness. In fact, common observation suggests that only a small proportion of the stimuli and responses involved in automatic processing ever enter into focal attention. However, a concept of automatic processing provides a means of making the conclusions of the present experiments and those of Pashler more plausible.

We propose that the human has two separate processing systems: one that is automatic and the other that corresponds to focal attention and the conscious noting of stimuli and responses. In contrast to the automatic, the attentional system is involved in the learning of new behaviors and is necessary for complex mental operations. Furthermore, these two processing systems operate concurrently. The automatic system is not a precursor or an initial stage in the attentive system. The two systems are separate. If the attentive system is directed to stimuli, such as discrimination between targets in a choice RT experiment, the attentive system controls the responses, but the automatic system also processes the stimuli even though the product of its processing is overridden by the attentive system. If the attentive system is directed to the automatic system, its behaviors, or the stimuli controlling them, the attentive system overrides the automatic in terms of controlling overt behavior and responses to the attended stimuli.

The implication of such a conception of two separate systems is that, when the attentive system is directed to a stimulus, its processing of that stimulus is largely independent of the processing that is occurring or has already occurred in the automatic system. In other words, with attentional processing, it is as though that stimulus had just occurred. Attentional processing is, for the most part, unable to benefit or use the processing that may have already occurred in the automatic system. We believe that this is what the results of our three experiments and those of Pashler (1984) imply.

This conception provides a means of accounting for the results of our Experiments 2 and 3, in which we found that the $T_{1}-T_{2}$ conditions (one target is substituted for the other target) had shorter substitution intervals than did the N-T conditions (target substituted for a noise letter). In both experiments, the former condition showed a significant increase in target RT at preview times of only $100 \mathrm{msec}$, whereas the N-T condition was still at the level of the control condition. This has been a consistent finding in several pilot experiments and in several subsequent experiments, the results of which we plan to report in future articles. In all cases, the substitution interval is shorter when the target for that trial is preceded by the other target than when it is preceded by a noise letter.

The difference in substitution interval between these two conditions is not readily accountable in terms of a process- 
ing difference for the target. The targets that replace the original letters in the cued location are the same across conditions. The conditions differ only in terms of whether the target replaces the alternative target letter or replaces a noise letter. The noise and target letters, of course, differ in shape, but this would not appear to be relevant. What does appear to be a critical difference is whether the replaced or original letter had an experimentally relevant response. An original target letter did, whereas a noise letter did not.

This pattern of results can be explained by assuming that the replaced letter was identified by the automatic system during the preview time or the substitution interval. Because the replaced letter in the $T_{1}-T_{2}$ condition was a target with an experimentally relevant response, the automatic identification of this letter would prime its associated response (e.g., Coles, Gratton, Bashore, C. W. Eriksen, \& Donchin, 1985; C. W. Eriksen, Coles, Morris, \& O'Hara, 1985). When the subsequent target letter is identified by the attentive system, the subject's signifying response for this target would be inhibited and the response slowed by the competing prime in the alternative response (i.e., response competition). In the $\mathrm{N}-\mathrm{T}$ condition, this response competition would not occur, because the automatic identification of the noise letter does not prime either of the responses by which the subject signifies his discrimination. Thus, the slower responses obtained in the $T_{1}-T_{2}$ conditions with $100-m s e c$ preview time are due not to slower attention system processing than occurs in the $\mathrm{N}-\mathrm{T}$ condition, but to competition in the response systems arising from the automatic identification of the original letter.

We have previously obtained evidence of the separate but concurrent processing by the automatic and the attenional systems (B. Eriksen, C. W. Eriksen, \& Hoffman, 1986). In these experiments, the Sternberg memoryscanning task was employed. The procedure was modified by presenting a noise letter along with the target letter. The noise letter could be either response compatible with the target letter or incompatible. For example, if the target letter was a member of the memory set, a compatible noise letter would be a member of the memory set. An incompatible noise letter would not be a member of the memory set. For all memory-set sizes, RT was elevated if the noise letter was response incompatible with the target (for both positive and negative trials) relative to response-compatible noise letters, but the slopes of the RT-set-size functions were not affected by response compatibility.

This result was consistent with an interpretation that says that the noise letter was processed by the automatic system on the basis of familiarity, much as has been suggested by Atkinson, Hermann, and Wescourt (1974), with the consequent priming of the relevant response. If this response was different from the response appropriate for the target, response competition occurred. The attentive system also processed the target letter and was able to screen out the irrelevant noise letter from the memory- scanning operation. Thus, the slopes of the RT-set-size functions were unaffected by the compatibility of the noise letters, but the signifying responses, when they were emitted, were subject to the response-competition effect arising from the concurrent automatic processing.

We would suggest that at least a significant source of the conflicting evidence for early- and late-selection models of attention results from confounding the contributions of automatic processing with measures of focal attention. Often when we think we are studying focal attention, the experimental paradigm has not been successful in excluding the products of the automatic system.

\section{REFERENCES}

Atkinson, R. C., Hermann, D. J., \& Wescourt, K. T. (1974). Search processes in recognition memory. In R. L. Solso (Ed.), Theories in cognitive psychology: The Loyola symposium (pp. 101-146). Potomac, MD: Erlbaum.

Averbach, E., \& Coriell, A. S. (1961). Short-term memory in vision. Bell System Technical Journal, 40, 309-328.

Colegate, R., Hoffman, J. E., Eriksen, C. W. (1973). Selective encoding from multielement visual displays. Perception \& Psychophysics, 14, 217-224.

Coles, M. G. H., Gratton, G., Bashore, T. R., Eriksen, C. W., \& Donchin, E. (1985). A psychophysiological investigation of the continuous flow model of human information processing. Journal of Experimental Psychology: Human Perception \& Performance, 11, 529-553.

Eriksen, B. A., \& Eriksen, C. W. (1974). The importance of being first: A tachistoscopic study of the contribution of each letter to the recognition of four-letter words. Perception \& Psychophysics, 15, 66-72.

Eriksen, B., Eruksen, C. W., Hoffman, J. E. (1986). Recognition memory and attentional selection: Serial scanning is not enough. Journal of Experimental Psychology: Human Perception \& Performance, $12,476-483$.

Eriksen, C. W., \& Colegate, R. (1971). Selective attention and serial processing in briefly presented visual displays. Perception \& Psychophysics, 10, 321-326.

Eriksen, C. W. Coles, M. G. H., Morris, L. R., O'Hara, W. P (1985). An electromyographic examination of response competition. Bulletin of the Psychonomic Society, 23, 165-168.

Eriksen, C. W., Goettr, B., St. James, J. D., \& Fournier, L. R. (1989). Processing redundant signals: Coactivation, divided attention, or what? Perception \& Psychophysics, 45, 356-370.

Eriksen, C. W., \& Hoffman, J. E. (1973). The extent of processing of noise elements during selective encoding from visual displays. Perception \& Psychophysics, 14, 155-160.

Eriksen, C. W., \& Rohrbaugh, J. W. (1970). Visual masking in multielement displays. Journal of Experimental Psychology, 83, 147-154.

ERIKSEN, C. W., \& SCHULTZ, D. W. (1978). Temporal factors in visual information processing. In J. Requin (Ed.), Attention and performance VII (pp. 1-26). New York: Academic Press.

ERIKSEN, C. W., SCHULTZ, D. W. (1979). Information processing in visual search: A continuous flow conception and experimental results. Perception \& Psychophysics, 25, 249-263.

ERIKSEN, C. W., SPENCER, T. (1969). Rate of information processing in visual perception: Some results and methodological considerations. Journal of Experimental Psychology Monographs, 79(Pt. 2), 1-16.

Eriksen, C. W., \& WebB, J. M. (1989). Shifting of attentional focus within and about a visual display. Perception \& Psychophysics, 45, 175-183.

ERIKSEN, C. W., \& YEH, Y. (1985). Allocation of attention in the visual field. Joumal of Experimental Psychology: Human Perception \& Performance, 11, 583-597. 
Fournier, L. R., \& Eriksen, C. W. (in press). Coactivation in the perception of redundant targets. Journal of Experimental Psychology: Human Perception \& Performance.

Hoffman, J. E. (1975). Hierarchical stages in the processing of visual information. Perception \& Psychophysics, 18, 348-354.

Kinchla, R. A. (1974). Detecting target elements in multi-element arrays: A confusability model. Perception \& Psychophysics, 15, 149-158.

LABERGE, D. (1973). Attention and the measurement of perceptual learning. Memory \& Cognition, 1, 268-276.

Murphy, T. D., \& EruKsen, C. W. (1987). Temporal changes in the distribution of attention in the visual field in response to precues. Perception \& Psychophysics, 42, 576-586.

Pashler, H. (1984). Evidence against late selection: Stimulus quality effects in previewed displays. Journal of Experimental Psychology: Human Perception \& Performance, 10, 429-448.

Rohrbaugh, J. W., \& Eriksen, C. W. (1975). Reaction time measurement of temporal integration and organization of form. Perception \& Psychophysics, 17, 53-58.

Shaw, M. L. (1978). A capacity allocation model for reaction time. Journal of Experimental Psychology: Human Perception \& Performance, 4, 586-598.

ShIFFrIN, R. M. (1988). Attention. In R. C. Atkinson, R. J. Herrnstein, G. Lindsay, \& R. D. Luce (Eds.), Stevens' Handbook of Experimental Psychology. New York: Wiley.
ShifFrin, R. M., \& GARDNER, G. T. (1972). Visual processing capacity and attentional control. Journal of Experimental Psychology, 93, $72-82$.

ShifFrin, R. M. \& SCHNEIDER, W. (1977). Controlled and automatic human information processing: II. Perceptual learning, automatic attending, and general theory. Psychological Review, 84, 127-190.

SPENCER, T., \& SHUNTICH, R. (1970). Evidence for an interruption theory of backward masking. Journal of Experimental Psychology, 85, 198-203.

SPERLING, G. (1960). The information available in brief visual presentations. Psychological Monographs, 74, 498.

Treisman, A., \& Gelade, G. (1980). A feature-integration theory of attention. Cognitive Psychology, 12, 97-136.

TSAL, Y. (1983). Movements of attention across the visual field. Journal of Experimental Psychology: Human Perception \& Performance, 9, 523-530.

VAN DER HeIJDEN, A. H. C. (1984). Postcategorical filtering in a barprobe task. Memory \& Cognition, 12, 446-457.

van der Heijden, A. H. C., Schreuder, R., de Loor, M., \& HaGenzieker, M. (1987). Early and late selection: Visual letter confusions in a bar-probe task. Acta Psychologica, 65, 75-89.

(Manuscript received June 28, 1989;

revision accepted for publication December 12, 1989.) 